\title{
PHYSICAL AND MECHANICAL PROPERTIES OF COMPOSITE BRICK FROM CEMENT MORTAR, FLY ASH AND RUBBER CRUMBS
}

\author{
Adrian Bustamante ${ }^{1}$, Greg Mark Dablo ${ }^{2}$, Romel Sia ${ }^{3}$, Renato Arazo ${ }^{4}$ \\ ${ }^{1}$ MS Environmental Engineering Student, University of the Philippines, Philippines \\ ${ }^{2}$ BS Environmental Engineering Graduate, MOSCAT, Philippines \\ ${ }^{3}$ BS Environmental Engineering Graduate, MOSCAT, Philippines \\ ${ }^{3}$ Dean, Institute of Engineering and Technology, MOSCAT, Philippines
}

\begin{abstract}
Responding to the need of minimizing the extraction of natural resources like sand and lime, this study attempted to use industrial wastes such as fly ash and rubber crumbs as substitute materials in making composite brick. A composite brick was produced by varying the rubber crumbs composition, as sand substitute in the mixture, from 10-30 wt.\% relative to total aggregate weight. Fly ash, 20 wt.\% relative to cement and fly ash weight, was used as binder substitute. After 28 days of curing, composite brick was tested in terms of compressive strength, density and water absorption capacity. Compressive test showed that the brick can only be used in less impacted area considering that it does not meet the minimum standard to be considered as substitute to the commercially available brick. A decreasing trend of its compressive strength is observed as the amount of rubber crumbs increases from 10 to $30 \%$ of the total aggregate weight. The addition of light rubber crumbs and fly ash desirably decrease the density of the composite brick when compared to those commercially sold in the market. Water absorption test revealed that the produced composite brick is more efficient in minimizing water absorption. This study demonstrated that composite brick can be made using industrial wastes as substitute for aggregate and binder, with huge implication in brick concrete making.
\end{abstract}

Keywords: Composite brick, rubber crumbs, fly ash, and concrete brick

\section{INTRODUCTION}

Concrete brick is a common building material generally composed of sand as aggregate, cement as binder and water which forms a durable stone-like mass material when it hardens. Sand and cement are the most common elements used for construction. In the past decades, rapid urbanization has led to an increase demand for river sand as a source of construction material. This has resulted to excessive sand mining activities which distort natural equilibrium of the stream.

Cement, as main component of concrete, is not an environment friendly material since it emits tremendous amount of carbon dioxide $\left(\mathrm{CO}_{2}\right)$ during production. It is estimated that the production of each ton of cement clinker emits approximately one ton of $\mathrm{CO}_{2}$ and other greenhouse gases (GHGs) to the atmosphere. It constitutes 5-8\% emission of $\mathrm{CO}_{2}$ worldwide which results to massive accumulation of these gases into the atmosphere causing global warming [1].

Mining of minerals for cement making causes environmental destruction, and in some cases, it is being worsened due to lack of information on proper extraction. Besides, continuous construction of infrastructures causes more volume of minerals (lime) to be extracted in quarry sites which resulted to destruction of mountains and river basins [2].

The world's yearly cement output in the last decade was 1.5 billion tons [3] and is continually growing year after year. It is estimated that by year 2050 the need of cement for concrete making will be towering to approximately 18 billion tons. Because of this huge cement demand coupled with the diminishing supply of natural resources, prices would inevitably continue to increase which eventually affect economic and environmental sustainability. Thus, several studies have been conducted to find alternatives of sand and cement for the production of concrete. One of the solutions is utilization of discarded materials such as fly ash and scrap tire to partially substitute cement and sand in concrete making. The use of these substitute materials will not only produce new engineering material but also significantly reduce the problem on waste disposal such as air pollution from scrap tire burning and water pollution due to fly ash contamination. This work aims to produce a composite brick where rubber crumbs is partly used as aggregate substitute and fly ash as part of the binder.

\section{MATERIALS AND METHODS}

\subsection{Preparation of Raw Materials}

Rubber crumbs was collected from tire recapping center in Cagayan de Oro City, Philippines. To achieve uniformity of rubber crumbs, the No. 15 wire mesh was used in sieving. Particles sizes that pass through the sieve were used as substitute aggregate in the composite brick making.

Fly ash was collected from STEAG Coal Power Plant in San Martin, Villanueva, Misamis Oriental, Philippines. 


\subsection{Composite Brick Making}

The brick was made in a 1:2 ratio ( 1 unit weight of binder for every 2 unit weight of aggregate). In terms of binder, only $80 \mathrm{wt} . \%$ was cement and the remaining $20 \mathrm{wt} . \%$ was fly ash as binder substitute. For the aggregate, the sand was substituted by rubber crumbs from 10-30 wt.\%. Table 1 shows the component of each mixture.

Table-1. Aggregate and binder component of each composite brick mixture

\begin{tabular}{lrrrrr}
\hline \multirow{2}{*}{ Mixture } & \multicolumn{2}{c}{ Aggregate, wt.\% } & & \multicolumn{2}{c}{ Binder, wt.\% } \\
\cline { 2 - 3 } \cline { 5 - 6 } & $\begin{array}{c}\text { Crumb } \\
\text { Rubber }\end{array}$ & Sand & & Fly ash & Cement \\
\hline Mixture 1 & 10 & 90 & & 20 & 80 \\
& $(113.3 \mathrm{~g})$ & $(1019.7 \mathrm{~g})$ & & $(113.3 \mathrm{~g})$ & $(453.2 \mathrm{~g})$ \\
Mixture 2 & 20 & 80 & & 20 & 80 \\
& $(226.6 \mathrm{~g})$ & $(906.4 \mathrm{~g})$ & & $(113.3 \mathrm{~g})$ & $(453.2 \mathrm{~g})$ \\
Mixture 3 & 30 & 70 & & 20 & 80 \\
& $(339.9 \mathrm{~g})$ & $(793.1 \mathrm{~g})$ & $(113.3 \mathrm{~g})$ & $(453.2 \mathrm{~g})$ \\
\hline
\end{tabular}

The cement, fly ash, sand, rubber crumbs, and sufficient water were mixed thoroughly until obtaining homogenous concrete mixture. With the frame measuring 8" length, 3" width, and 2" depth; the mixture was poured, manually compressed by the pallet and set aside in a safe place.

After 24 hours, the composite brick was removed from the molder. It was then cured in a wet environment by submerging it in water for 28 days. Eventually, the produced wet composite brick was dried to completely eliminate water. The dried brick was then used for quality testing and analysis.

\subsection{Quality of Produced Composite Bricks}

The produced bricks were tested in terms of its compressive strength at LYL Development Corporation Testing Laboratory Services at KIMWA Compound, Baloy, Cagayan de Oro City, Philippines.

Density of the composite brick was calculated after complete drying using the formula shown in Eq. 1 below.

Density=mass $/$ volume

Eq 1

Water absorption capacity was determined by submerging bricks in water for 12 hours. After which, the brick's excess water was drained and it was dried by damp cloth to remove visible surface water. The weight of the wet brick was determined and recorded as saturated weight (Ws). Eventually, the brick was dried and and the dry weight $(W d)$ was determined. Water absorption was calculated using Eq. 2 below:

Water Absorption, \%=(Ws-Wd)/Wd x 100 Eq. 2

\subsection{Statistical Analysis}

Sample bricks from each mixture were tested, in three replications, to determine the compressive strength, density, and water absorption capacity. Analysis of Variance (ANOVA), at $5 \%$ level of significance, was employed in comparing the properties of bricks from three different mixtures. One sample t-test was employed in comparing the properties of the produced composite brick and the standard value.

\section{RESULTS AND DISCUSSION}

\subsection{Physical and Mechanical Properties of Composite Bricks}

Table-2. Physical and mechanical properties of bricks

\begin{tabular}{lrrr}
\hline \multirow{2}{*}{ Properties } & \multicolumn{3}{c}{ Experimental Result } \\
\cline { 2 - 4 } & Mixture 1 & Mixture 2 & Mixture 3 \\
\hline $\begin{array}{l}\text { Compressive } \\
\text { Strength, psi }\end{array}$ & $1074.14 \pm 52.7$ & $586.99 \pm 30.4$ & $405.11 \pm 35.3$ \\
Density, kg/m ${ }^{3}$ & $1716.58 \pm 26.3$ & $1661.89 \pm 6.7$ & $1484.37 \pm 17.0$ \\
& & & \\
Water & & & \\
$\begin{array}{l}\text { Absorption, } \\
\text { wt.\% }\end{array}$ & $4.59 \pm 0.75$ & $5.25 \pm 0.91$ & $7.20 \pm 0.78$ \\
\hline
\end{tabular}

As shown in Table 2, mixture 1 with $10 \%$ rubber crumbs has an average compressive strength of 1074.14 psi; mixture 2 with $20 \%$ rubber crumbs has a mean compressive strength of 1074.14 psi; and mixture 3 with $30 \%$ rubber crumbs has the lowest compressive strength of $405.11 \mathrm{psi}$. The average values of compressive strengths were inversely proportional with the percentage of rubber crumbs replacement. The compressive strength of the composite brick decreased with an increase in the amount of rubber crumbs.

The primary cause of the strength reduction is the poor adhesion of the cementitious products to the surface of the rubber particles [4]. This is also because rubber easily cracks when subjected to load which accelerates failure of the specimen [5].

Densities of three mixtures were decreasing with increasing amount of rubber crumbs (Table 2). Numerically, the density decreased from $1716.58 \mathrm{~kg} / \mathrm{m}^{3}$ (mixture 1) to $1484.37 \mathrm{~kg} / \mathrm{m}^{3}$ (mixture 3).

Density reduction was expected because of the low specific gravity of the rubber aggregates with respect to that of the sand [5]. Furthermore, rubber particles were non-polar in nature which has the ability to attract and entrap air in the rough surface causing the increase in air content and reducing the density of the specimen [6].

Reduction in density is a desirable feature in a number of applications, including architectural applications such as nailing concrete, false facades, stone backing and interior construction [6], as well as precast concrete bricks or blocks and slabs [5].

Water absorption capacities in three mixtures were increasing with increasing percent component of rubber crumbs (Table 2). The water absorption of mixture 1,2 , and 
3 were $3.81 \%, 5.25 \%$, and $7.20 \%$, respectively. This means that the composite brick containing more percentage of rubber absorbs more water during wet curing or hydration process.

The reason for this behavior was the existence of capillaries which were filled with water in the concrete containing rubber during wet curing [7]. In addition, poor bonding between rubber particles and cement paste resulted to rubber-cement surface interface which acts as the bedding for pressurized water to flow around the concrete matrix.

\subsection{Comparison of Bricks Properties According to}

\section{Mixtures}

ANOVA result in comparing the compressive strength of the bricks showed a p-value of 2.5exp-06 which is significantly lower at $5 \%$ level of significance. It proved that there is a significant variation in the mean values of the compressive strengths between mixtures. This means that the compressive strength of the composite brick is significantly affected by the raw materials it was made of. Those bricks with little amount of rubber crumbs has high compressive strength.

Table-3: Analysis of Variance (ANOVA) in comparing the properties of bricks produced from three mixtures

\begin{tabular}{lrr}
\hline Property & F value & P value \\
\hline Compressive strength & 217.63 & $2.5 \mathrm{E}-06$ \\
Density & 129.60 & $1.16 \mathrm{E}-05$ \\
Water absorption & 4.65 & 0.018703 \\
\hline
\end{tabular}

Densities of the composite bricks from three mixtures reveal significant difference with a p-value of 1.16exp-05 (Table 3). It implies that the density of the composite brick significantly decreased as the amount of rubber crumbs was increased.

The p-value of 0.018703 means that there is significant variation in the water absorption capacities of bricks from three mixtures (Table 3). This means that the composite brick with fewer amounts of rubber crumbs can withstand better in retarding water to penetrate into the pore spaces of the brick.

\subsection{Comparison of Bricks Properties to the}

\section{Standard}

\subsubsection{Compressive Strength of Bricks and the \\ Standard}

Table 4 shows probability values in comparing bricks from three mixtures to the standard compressive strength of 2000 psi. Brick produced using mixture 1 has p-value of 0.0538 which is statistically near to $5 \%$ level of significance. This means that brick compressive strength mean value of 1074.147 psi is not significantly different to the standard value of 2000 psi. While the compressive strengths of bricks produced using mixtures 2 and 3 were significantly lower compared to the test value with p-values of 0.0006 and 0.0008 , respectively.
Table-4: Comparison of the compressive strength of produced composite bricks and the standard

\begin{tabular}{lrrr}
\hline Parameter & Mixture 1 & Mixture 2 & Mixture 3 \\
\hline Test standard, psi & 2000 & 2000 & 2000 \\
Experimental Result & & & \\
$\quad$ Mean, psi & 1074.147 & 586.993 & 405.11 \\
StDev, psi & 52.699 & 30.426 & 35.299 \\
SE Mean, psi & 30.426 & 17.566 & 20.38 \\
Observed Dif*, psi & -925.853 & -1413.007 & -1594.89 \\
t -value & -4.136 & -34.897 & -39.004 \\
P-value & 0.0538 & 0.0008 & 0.0006 \\
\hline
\end{tabular}

This proved that among the bricks produced using three different mixtures, only the brick from mixture 1 with lowest amount of rubber crumbs replacement can somehow withstand axially when subjected to pushing force and allowable load before it crushes or breaks.

The result implied that bricks with rubber crumbs generally cannot withstand to load when used in the same way as most brick is used. This kind of composite brick can be used in areas that carries lighter load.

\subsubsection{Density of Bricks and the Standard}

In terms of density, the probability values of the bricks from three mixtures when compared to standard were less than 0.05 (5\% level of significance). The p-values in comparing brick's density standard value and those composite produced from mixtures 1 to 3 were $0.0028,0.0002$, and 0.0004 , respectively. These imply that the densities of the three bricks produced at different mixtures were significantly lower compared to the standard value.

Reduction of densities of the produced composite bricks was due to the influence of the amount of rubber crumbs in the mixtures. Though fly ash helped increase the density by filling up the voids in the composite matrix, it was not enough to compensate the reduction caused by rubber particles.

Table-5. Comparison of the density of the produced composite bricks and the standard

\begin{tabular}{lrrr}
\hline Parameter & Mixture 1 & Mixture 2 & Mixture 3 \\
\hline Test standard, kg/m & 2000 & 2000 & 2000 \\
Experimental Result & & & \\
Mean, $\mathrm{kg} / \mathrm{m}^{3}$ & 1716.58 & 1661.893 & 1484.373 \\
StDev, $\mathrm{kg} / \mathrm{m}^{3}$ & 26.31 & 6.681 & 16.929 \\
SE Mean, $\mathrm{kg} / \mathrm{m}^{3}$ & 15.19 & 3.857 & 9.774 \\
Observed Dif*, $\mathrm{kg} / \mathrm{m}^{3}$ & -283.42 & -338.11 & -515.627 \\
$\mathrm{t}-$ value & -18.658 & -87.657 & -52.756 \\
P-value & 0.0028 & 0.0002 & 0.0004 \\
\hline
\end{tabular}


Because there was poor bonding between rubber particles and cement, rubber crumbs acted as void in the cement matrix which increased its volume and resulted to reduction of the brick's density [5]. This finding was consistent to other findings [8] which stated that rubber particles provide a porous effect between the rubber and the cement matrix since it is less stiff than cement.

This result is favorable producing lightweight construction material with great advantage in handling and transportation. Lightweight materials can easily be handled and transported which saves fuel and energy. It may also improve structural efficiency in terms of strength/weight ratios resulting to load reduction in the structure and substructure, fewer structural components resulting to more usable space in the structure, and reduction in the number and size of reinforcements.

\subsubsection{Water Absorption of Bricks and the Standard}

Comparison of the brick's water absorption standard and those produced from mixtures 1 and 2 revealed $p$-values lower than 0.05 (5\% level of significance), 0.0158 and 0.0346 , respectively. This means that bricks produced using these mixtures have less water absorption capacity when compared to allowable standard. Simply, $4.59 \%$ and $5.24 \%$ water absorption capacities of bricks from mixture 1 and 2 respectively were statistically lower than the standard value of $8 \%$. For brick produced using mixture 3, it has a p-value of 0.2152 which is significantly higher than the $5 \%$ level of significance. This means that there is no strong evidence to show that water absorption capacity of brick from mixture 3 (mean $=7.19 \%)$ is better than the set standard value of $8 \%$.

Table-6: Comparison of water absorption capacity of the produced composite bricks and the standard

\begin{tabular}{lrrr}
\hline Parameter & Mixture 1 & Mixture 2 & Mixture 3 \\
\hline Test standard, \% by mass & 8 & 8 & 8 \\
Experimental Result & & & \\
Mean, \% by mass & 4.59 & 5.247 & 7.197 \\
St Dev, \% by mass & 0.751 & 0.911 & 0.777 \\
SE Mean, \% by mass & 0.4334 & 0.526 & 0.448 \\
Observed Dif., wt.\% & -3.41 & -2.753 & -0.803 \\
t -value & -7.8757 & -5.233 & -1.7909 \\
P-value & 0.0158 & 0.0346 & 0.2152 \\
\hline
\end{tabular}

Results indicated that the bricks produced from three mixtures had desirable water absorption properties with values lower than the maximum allowable requirement. Water absorption is one of the most significant parameters in developing good bond strength between bricks and mortars. A brick with low water absorption capacity better resist to volume changes which prevents possible cracking of the bricks and structural damage in buildings. It would likewise prevent cracking in the event of freezing and thawing due to less water inside the pores.

The result further showed that the water absorption capacity is not extremely low with values from 4.59 to $7.20 \%$. This is desirable result because too little water absorption is undesirable because rain water that enters the pores would tend to run off very quickly towards the joints and may find its way into the building as well as reduce the durability of the mortar.

\section{CONCLUSION}

Based on the experimental work and from the analyses of results obtained, the following conclusions were drawn:

[1]. The addition of rubber crumbs leads to the undesirable reduction of the compressive strength of the composite brick which attributed to the poor binding between rubber and cement in cement-rubber interface. With this, the produced composite brick limits its use if the primary requirement is the strength.

[2]. There is a desirable reduction of the density with the increase of rubber crumbs replacement primarily due to lower specific gravity of rubber compared to sand.

[3]. The water absorption unfavorably increases as the amount of rubber crumbs increases. This is because there were many voids that were ready to fill with water during hydration and wet curing.

[4]. Though the addition of rubber crumbs increases the voids of the specimen, the produced bricks still have desirable water absorption capacity with value lower than the maximum allowable standard value. This proves that the incorporation of rubber crumbs in brick making improves water absorption during brick laying. The excess absorbed water during hydration can result in water concentration resulting to leakage through brick and brick-mortar interface.

\section{ACKNOWLEDGMENT}

The authors would like to acknowledge the technical help of Engr. Dennis T. Yamuta, Engr. Allen Rhay B. Bayantong, Engr. Jose Rey Q. Joyno and Dr. Ronelo G. Cablinda.

\section{REFERENCES}

[1]. Summerbell, D. et al. (2012). "Performance variation: $\mathrm{CO}_{2}$ emissions from cement manufacturing. University of Cambridge.

[2]. Esguerra, N. et al. (2008). "Characterizing the environmental effects of the quarrying industry: The case of strategic quarry sites in the Ilocos Region", UNP Research Journal Vol. 17. Retrieved: February 23, 2014.

[3]. Mehta, P. \& Monteiro, P. (2004). "Concrete: Microstructure, properties, and materials". Retrieved: July $17, \quad 2014$ from: http://www.ce.berkeley.edu/ paulmont/165/review2.pd $\mathrm{f}$

[4]. Thomas, B. et al. (2014). "Strength, abrasion and permeation characteristics of cement concrete containing discarded rubber fine aggregates", Construction and Building Materials, Vol. 59, pp204212. Retrieved: January 03, 2015.

[5]. Mavroulidou, M. \& Figueiredo, J.(2010). "Discarded 
tyre rubber as concrete aggregate: A possible outlet for used tyres", Global NEST Journal, Vol. 12, No. 4, pp359-367. Retrieved: July 15, 2014.

[6]. Siddique, R. \& Naik, T. (2004). "Properties of concrete containing scrap-tire rubber - An overview", Waste Management, Vol. 24, pp563-569. Retrieved: April 27, 2014.

[7]. Ganjian E. et al. (2007). "Scrap-tyre-rubber replacement for aggregate and filler in concrete", Construction and Building Material, Vol. 23, pp.18281836. Retrieved: January 03, 2015.

[8]. Yilmaz, A. \& Degirmenci, N. (2008). "Possibility of using waste tire rubber and fly ash with Portland cement as construction materials", Waste Management, Vol. 29, pp1541-1546. Retrieved January 03, 2015.

\section{BIOGRAPHIES}

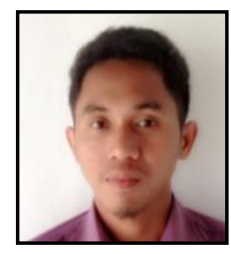

Engr. Adrian Bustamante is presently a graduate student of the University of the Philippines Diliman taking up MS Environmental Engineering. He obtained his BS Environmental Engineering at MOSCAT.

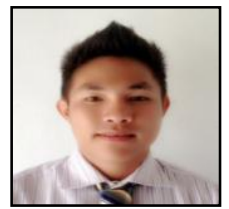

Engr. Greg Mark Dablo is a graduate of the degree BS in Environmental Engineering at Misamis Oriental State College of Agriculture and Technology (MOSCAT).

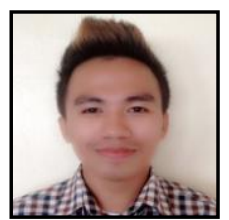

Engr. Romel Sia is a graduate of the degree BS in Environmental Engineering at Misamis Oriental State College of Agriculture and Technology (MOSCAT).

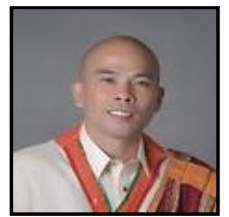

Dr. Renato Arazo is currently the Dean of Institute of Eng'g. and Technology of MOSCAT. He was a visiting scholar of Texas A\&M University, Texas, USA. 